\title{
Методы государственного регулирования предпринимательской деятельности: теоретические подходы и опыт реализации в развитых странах ${ }^{1}$
}

\section{София Калинина* , Екатерина Кузнецова}

Вологодский научный центр Российской академии наук, г.Вологда, Россия

\author{
Информация о статье \\ Поступила в редакияю: \\ 28.10 .2020 \\ Принята \\ к опубликованию: \\ 01.12 .2020 \\ УДК 338.242 .4 \\ JEL L26
}

\begin{abstract}
Аннотация
В работе систематизирован зарубежный опыт в направлении использования методов и инструментов государственного управления мальм и средним предпринимательством. Статья основана на применении прочессного подхода $\kappa$ изучению вопроса исследования, в рамках которого акцентируется воздействие субъекта на объект, то есть под управлением в данном исследовании будет пониматься прочесс воздействия субъекта управления на управляемый объект для достижения определенной цели, при наличии обратной связи, осуществляемого с учетом воздействия внешней среды. Результаты представленного исследования вносят вклад в развитие и систематизацию теории $и$ практики предпринимательства. Создание благоприятных условий, в частности благодаря изучению зарубежного опьтта, будет способствовать развитию как малого и среднего предпринимательства, так и динамичному прогрессивному развитию территории, повышая тем самым благосостояние её населения. Будущими направлениями исследования станут анализ и оценка инфраструктуры поддержки и управления предпринимательской деятельности на локальной территории региона.
\end{abstract}

Methods of Entrepreneurial Activity State Regulation: Theoretical Approaches and Implementation Experience in Developed Countries

Sofia Kalinina, Ekaterina Kuznetsova

\section{Abstract}

The purpose of this paper is to systematize foreign experience in applying the public management methods and tools for small and medium-sized businesses. The main research methods were as follows: a group of general scientific methods within the framework of comparative, logical and statistical analysis, as well as the structure analysis; a group of empirical methods, including a review of the literature and performance. A combination of the following scientific methods was used to process the factual information: dialectical, logical, comparative, method of scientific generalizations, as well as the tabular analysis. The sources were the results of the scientific

\footnotetext{
${ }^{1}$ Статья подготовлена в рамках государственного задания № 0168-2019-0006 «Управление процессами структурной трансформации экономики регионов на основе развития малого и среднего предпринимательства».

* Автор для связи: sonechka-kalinina1997@mail.ru DOI: https://dx.doi.org/10.24866/2311-2271/2020-4/100-112
} 
research in studying the concept of "public administration method" and more specialized methods of public administration - administrative-legal and economic, as well as the regulations of the executive authorities and the official published reports of the Government Banks. The research methodology is based on the works of domestic and foreign scientists in the field of public administration, based on administrative-legal and economic methods to stimulate the entrepreneurial activity in the small business sector. This paper is based on the application of the process approach to studying the research issue, which emphasizes the impact of the subject on the object, that is, management in this study will be understood as the process of the control subject impact on the controlled object to achieve a certain goal, with feedback, carried out in response to the impact of the external environment. The results of the research contribute to the development and systematization of the entrepreneurship theory and practice. The creation of favorable conditions, in particular due to the study of foreign experience, will contribute to the development of both small and medium-sized businesses and the area progressive and dynamic development, thereby improving the well-being of its population. Future areas of the research will include the analysis and evaluation of the business support and management infrastructure in the local area of the region.

\section{Введение}

Повышение уровня развития территории является важнейшей задачей государственной политики. Степень успешности решения этой задачи во многом определяется состоянием основополагающих факторов современной рыночной экономики. Важнейшим из них является предпринимательство. Особого внимания заслуживает его наиболее мобильная и способная быстро и оперативно реагировать на окружающие изменения категория - малое и среднее предпринимательство (далее - МСП).

В рыночной экономике малое и среднее предпринимательство составляет ведущий сектор, определяющий темпы экономического роста, структуру и качество валового внутреннего продукта. В соответствии с этим развитие данной категории отвечает общемировым тенденциям: поддержка и наращивание численности МСП; формирование гибкой экономики в сочетании с разнообразными формами собственности; реализация синтеза конкурентного рыночного механизма и государственного управления мелким, средним и крупным предпринимательством и т.д. (табл. 1) [1].

Таблий 1

Доля предпринимательства в экономике стран, 2018 2.

\begin{tabular}{|c|c|c|c|}
\hline \multirow{2}{*}{ Страны } & \multirow{2}{*}{$\begin{array}{c}\text { Доля работников в секторе МСП, } \\
\text { юр. лиц (\%) }\end{array}$} & \multicolumn{2}{|c|}{ Доля в ВВП страны (\%) } \\
\hline & & Крупного бизнеса & MCI \\
\hline Великобритания & 53,1 & 49 & 51 \\
\hline Германия & 63,1 & 47 & 53 \\
\hline Канада & 57,9 & 43 & 57 \\
\hline США & 53 & 49 & 51 \\
\hline Япония & 52,8 & 51 & 49 \\
\hline Италия & 78,6 & 38 & 62 \\
\hline Россия & 33 & 79 & 21 \\
\hline
\end{tabular}

Источник: составлено авторами на основе [1]

Именно МСП, не требующее крупных стартовых инвестиций и гарантирующее высокую скорость оборота ресурсов, способно наиболее быстро и эффективно решать проблемы реструктуризации экономики, формирования и насыщения рынка потребительских товаров в условиях ограниченности ресурсов [2]. Его деятельность играет немаловажную роль в ускорении инновационных процессов: осуществление разработок, внедрение результатов научноисследовательских работ в деятельность других участников рынка, а также в способности быстро реагировать на потребительские запросы, осваивая выпуск уникальной продукции или специфических услуг. 
Благодаря МСП создаётся большее количество новых рабочих мест в таких отраслях экономической деятельности как розничная и оптовая торговля, ремонт автомобилей и мотоциклов (занятость в ЕС - 20,7 млн чел.: 27\% на малых и 19\% на средних предприятиях), обрабатывающая промышленность (15,8 млн чел.: $14 \%$ и $33 \%$ соответственно), строительство (10,2 млн чел.: $14 \%$ и 7\% соответственно) и гостиничные услуги с общественным питанием (12\% и $6 \%$ соответственно $)^{2}$ [3].

Значительная доля малого и среднего предпринимательства, его производимых товаров и оказываемых услуг в составе валового внутреннего продукта в представленных зарубежных странах варьируется от 51 до 62\%, в России - 21\% (общая численность занятых в секторе МСП составила 19,1 млн чел. в первом полугодии 2019 г. ${ }^{3}$ ), что свидетельствует о крайне низком значении по сравнению с другими странами. Приведённые данные о внушительной доле МСП в экономике развитых стран указывают на его (МСП) ведущую роль в социальноэкономическом и политическом развитии данных территорий, ввиду того, что предприятия и организации составляют подавляющее большинство, обеспечивающее занятость наибольшей части экономически активного населения (52-79\% или $67 \%$ от всех занятых в ЕС в 2017 г. (83,9 млн чел.) $)^{2}$.

В Российской Федерации, несмотря на официальную статистику о сравнительно низкой доле малого и среднего предпринимательства в ВВП страны, активно оказывается поддержка предпринимательству. Из последнего - принятый Национальный проект «Малое и среднее предпринимательство и поддержка индивидуальной предпринимательской инициативы» ${ }^{4}$ до 2024 г., который направлен на всесторонне улучшение предпринимательского климата в России. Данный проект включает 5 федеральных проектов: «Расширение доступа субъектов МСП к финансовым ресурсам, в том числе к льготному финансированию», «Улучшение условий ведения предпринимательской деятельности», «Акселерация субъектов МСП», «Создание системы поддержки фермеров и развитие сельской кооперации», а также «Популяризация предпринимательства». Перечисленные пять проектов призваны увеличить численность занятых в сфере МСП до 25 млн чел., увеличить долю МСП в ВВП страны до $32 \%$, долю экспорта МСП - до 10\% от общего объёма.

Принятый Национальный проект свидетельствует о повышенном внимании государственных органов власти к вопросу развития и поддержки субъектов малого и среднего предпринимательства в направлении их роста и увеличения дохода, привлечения инвестиций, создания рабочих мест, запуска новых направлений работы, выстраивания долгосрочных связей и партнёрских отношений, как внутри страны, так и за её пределами и т.д.

Это связано прежде всего с тем, что развитое предпринимательство способно обеспечивать стабильность социально-экономического развития региона, ориентируясь на потребителя и неудовлетворённый спрос, содействовать структурной перестройке экономики, укреплению экономической базы регионов, создавать благоприятную среду для развития конкуренции, обеспечивать занятость значительной части населения и внедрять достижения научно-технического прогресса в смежные сферы человеческой деятельности.

В связи с этим стремление государственных органов власти к всесторонней поддержке предпринимательства обусловлено выбором образцовых и наиболее эффективных на практике методов управления, способных обеспечить

\footnotetext{
${ }^{2}$ Employment by enterprise size class across economic activities in the EU / Ec.europe.eu/eurostat (data obrashcheniya: 25.09.2020)

Единый реестр субъектов малого и среднего предпринимательства. URL: https://rmsp.nalog.ru/statistics.html (дата обращения: 30.09.2020)

${ }^{4}$ Национальный проект «Малое и среднее предпринимательство и поддержка индивидуальной предпринимательской инициативы» https://futurerussia.gov.ru/maloe-i-srednee-predprinimatelstvo (дата обращения: 28.09.2020 г.)
} 
развитие предпринимательской деятельности благодаря использованию зарекомендовавших себя в мировом опыте инструментов и механизмов регулирования.

Ввиду этого целесообразным видится рассмотрение вопроса зарубежного опыта реализации методов государственного управления предпринимательством. Цель данного исследования - систематизация зарубежного опыта в направлении использования методов и инструментов государственного управления малым и средним предпринимательством. Для достижения цели необходимо решить следующие задачи:

1) проанализировать определения «метода государственного управления» и выделить подходы к классификации обозначенных методов;

2) обратиться к содержанию базовых методов государственного управления: административно-правовых и экономических: определение и обоснование выбора;

3) представить реализацию данных методов через инструменты зарубежных федеральных органов исполнительной власти таких как Правительство, федеральное Министерство, правительственные организации и государственный гарантийный фонд, а также Правительственных банков в таких странах как США и Канада.

\section{Теория исследования}

Стоит отметить, что одним из важных инструментов управления экономикой региона является предпринимательская деятельность.

Предпринимательская деятельность как один из видов управляемых объектов нуждается в особых специальных методах государственного управления в связи со спецификой деятельности, осуществляемой субъектами предпринимательства.

В связи с этим, закономерным становится рассмотрение вопроса о существующих в теории и практике методов государственного управления, которые выражены в большом количестве многообразных трактовок понятия «метод государственного управления», подходов и классификаций методов, отражающих ту или иную сторону, связанную со спецификой предмета исследования (табл. 2).

Представленные в табл. 2 определения понятия во многом соотносятся, что позволяет выразить общие черты:

1) метод государственного управления есть способ (средство) достижения целей и осуществления функций государственной управленческой деятельности;

2) метод государственного управления реализуется органами государственной (исполнительной) власти и их должностными лицами в проделах своих полномочий и компетенций;

3) метод государственного управления применяется для целенаправленного воздействия на участников общественных отношений;

4) воздействие метода государственного управления призвано обеспечить эффективное урегулирование, охрану и защиту общественных отношений, а также использование ресурсов.

Выделенные черты позволили объединить их в одном определении, которого будем придерживаться на протяжении всего исследования: метод государственного управления - это правовые способы и средства властного воздействия органов государственного управления и должностных лиц в пределах своих полномочий и компетенций в установленном законом порядке на участников общественных отношений для их эффективного функционирования и использования ресурсов для достижения поставленных целей, решения задач и реализации функций государственного управления. 


\section{Трактовки к понятию «метод государственного управления»}

\begin{tabular}{|c|c|}
\hline Старилов Ю.Н. & $\begin{array}{l}\text { Представляет собой правовое средство, которое используется для дос- } \\
\text { тижения целей, решения задач и осуществления функций государствен- } \\
\text { ной управленческой деятельности. Данные методы применяются субъ- } \\
\text { ектами исполнительной власти и государственного управления, т.е. } \\
\text { субъектами административного права. }\end{array}$ \\
\hline Еропкин М.И. & $\begin{array}{l}\text { Способы целенаправленного воздействия на участников управленче- } \\
\text { ских отношений в целях обеспечения с их стороны поведения, необхо- } \\
\text { димого для решения задач, достижения целей, осуществления функций } \\
\text { управления. }\end{array}$ \\
\hline Козлов Ю.М. & $\begin{array}{l}\text { Средства практического осуществления деятельности по реализации } \\
\text { исполнительной власти; метод управления представляет собой предос- } \\
\text { тавленную субъектам государственно-управленческой деятельности } \\
\text { нормами административного права возможность результативно решать } \\
\text { стоящие перед ними задачи. }\end{array}$ \\
\hline Фиалковская И.Д. & $\begin{array}{l}\text { Метод способствует реализации функции в конкретном отношении (на- } \\
\text { пример, применение конкретной меры административного пресечения - } \\
\text { задержание гражданина за нарушение общественного порядка) }\end{array}$ \\
\hline $\begin{array}{l}\text { Бахрах Д.Н., Лунев А } \\
\text { Е., Пискотин М.И., } \\
\text { Ямпольская Ц.А. }\end{array}$ & $\begin{array}{l}\text { Организующее воздействие органа управления на подконтрольную сис- } \\
\text { тему, обязательное условие её деятельности, порядок наиболее эффек- } \\
\text { тивного использования ресурсов для достижения поставленных целей и } \\
\text { решения задач. }\end{array}$ \\
\hline Андрюхина Э.П. & $\begin{array}{l}\text { Комплекс средств, способ властного воздействия органов государствен- } \\
\text { ной власти на общественные отношения с целью обеспечения эффек- } \\
\text { тивного урегулирования, охраны и защиты общественных отношений. }\end{array}$ \\
\hline $\begin{array}{l}\text { Жеребцов А.Н., } \\
\text { Малышев Е.А. }\end{array}$ & $\begin{array}{l}\text { Юридически легитимированная совокупность средств, способов и } \\
\text { приёмов властного воздействия компетентного органа исполнительной } \\
\text { власти (должностного лица) на управляемую подсистему (объект } \\
\text { управления), определяющая условия и порядок её деятельности, наибо- } \\
\text { лее эффективное использование ресурсов для достижения поставленных } \\
\text { целей, решения задач и реализации функций. }\end{array}$ \\
\hline
\end{tabular}

Источник: составлено авторами

Остановимся на раскрытии содержания двух групп методов: административно-правовых и экономических, содержащих в себе отличительные способы и средства. Выбор обусловлен тем, что они образуют основу для создания и развития предпринимательства, а потому являются важнейшими среди представленных, т.к. их реализация сопровождается осуществлением государственных юридических властных полномочий органами государственного управления и их должностными лицами.

Ученые В.М. Манохин, Т.В. Закупень, И.В. Ершова, Л.А. Душакова, Г.Д. Ханатаев и др. рассматривают обозначенные методы как первоочередные в силу их применения на разных этапах управления предпринимательской деятельностью: от создания предприятия (компании) до его (её) ликвидации $[7,8]$.

Административно-правовые методы - это способы и средства прямого воздействия, выраженные в форме нормативно-правовых актов, рекомендаций, согласований, разрешений и т.д., осуществляемые органами исполнительной власти на соответствующие объекты управления. Описанные методы (по воздействию на объекты) подразделяется на обязывающие, уполномочивающие и поощряющие.

Экономические методы - это способы и средства экономического воздействия, направленные на материальные интересы и поведение субъектов предпринимательства для стимулирования их деятельности в целях достижения оптимальных результатов их функционирования с наименьшими требованиями и затратами. Данные методы занимают центральное место, что связано в первую 
очередь с экономическими отношениями и лежащими в их основе объективными потребностями и интересами людей.

В государственном управлении экономические методы выполняют роль несущей конструкции, в то время как административно-правовые - выступают индикаторами, задающими приоритетные направления структурных преобразований, поощряющими предпринимательскую деятельность, будучи значимыми амортизаторами, гасящими негативные эффекты $[9,10]$.

Рассмотрим реализацию выделенных групп методов в успешно развивающихся странах, где данные методы также широко применяются и способствуют повышению уровня развития, как самого предпринимательства, так и экономики в целом. В качестве территориальных объектов был выбраны Соединённые Штаты Америки и Канада, что обусловлено наличием у стран схожих инструментов и мер государственной поддержки предпринимательства, позволяющих добиваться успеха в данном секторе.

В конечном итоге систематизация в направлении использования административно-правовых и экономических методов и инструментов государственного управления функционированием малого и среднего предпринимательства в зарубежной практике позволит выделить особенности и схожие черты в системе поддержки предпринимательства.

\section{Методика}

Материалами исследования послужили работы российских учёных и практиков, а также нормативно-правовые акты и опубликованные ежегодные отчёты деятельности органов исполнительной власти, в которых раскрываются содержание административно-правовых и экономических методов государственного управления и основные способы, меры и инструменты реализации методов государственного управления функционированием малого и среднего предпринимательства за рубежом.

В работе нашли применение метод синтеза, использование которого позволило выделить общие черты в государственной поддержке МСП, а также метод анализа, графический и статистический (ряды динамики) методы, которые являются традиционными для исследований.

\section{Результаты исследования и их обсуждение \\ Соединённые Штаты Америки}

Соединённые Штаты Америки - государство, построенное на принципах свободного предпринимательства, где доминирующую роль занимает малое и среднее предпринимательство, составляющее порядка $50 \%$ от общего участия в ВВП страны.

Среди МСП, компании с менее чем 100 сотрудниками составляют 98,2\% (с менее чем 20 сотрудниками $=89 \%$ ) от общего числа всех предприятий малого бизнеса в стране. Это говорит о том, что небольшие компании несут ответственность за создание большого количества рабочих мест.

В силу сложившихся исторически и закреплённых законодательно принципов свободного предпринимательства, государственные органы власти Соединённых Штатов Америки разрабатывают и постоянно совершенствуют поддержку для субъектов, особенно малого и среднего предпринимательства, чтобы она всегда способствовала их эффективному функционированию. Несомненно, приоритетными в данном направлении остаются административно-правовые и экономические методы государственного управления и их соответствующие инструменты: утверждение государственных программ, введение налоговых льгот 
и преференций, а также действие индивидуальных условий для особых (частных) групп населения и многое другое.

Рассмотрим более подробно реализацию методов через инструменты государственного управления поддержки субъектов МСП на территории США (табл. 3).

Таблица 3

Методы, реализуемые государственными институтами и организациями в сфере МСП на территории США

\begin{tabular}{|c|c|c|}
\hline Методы & \multicolumn{2}{|c|}{$\begin{array}{l}\text { Инструменты } \\
\text { Закон о малом бизнесе (30 июля 1953); Закон об инвестициях в малый бизнес (1958); } \\
\text { Финансовый отчёт Агентства по делам малого бизнеса США за } 2019 \text { год (Small Busi- } \\
\text { ness Administration's Agency); Закон о внесении изменений в Закон о малом бизнесе с } \\
\text { целью повторной авторизации программы SCORE и для других целей (22 октября } \\
\text { 2019) }\end{array}$} \\
\hline 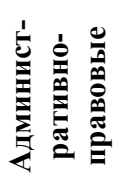 & \multicolumn{2}{|c|}{$\begin{array}{l}\text { Закон о малом бизнесе (30 июля 1953); Закон об инвестициях в малый бизнес (1958); } \\
\text { Финансовый отчёт Агентства по делам малого бизнеса США за } 2019 \text { год (Small Busi- } \\
\text { ness Administration’s Agency); Закон о внесении изменений в Закон о малом бизнесе с } \\
\text { целью повторной авторизации программы SCORE и для других целей (22 октября } \\
\text { 2019) }\end{array}$} \\
\hline \multirow{6}{*}{ 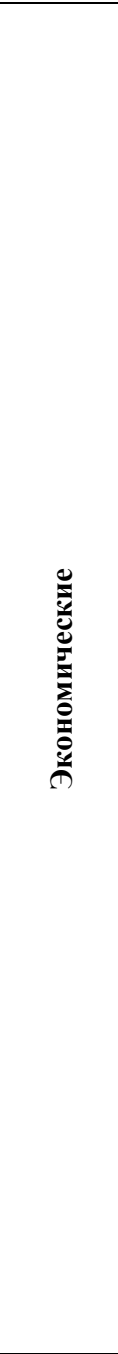 } & \multirow{6}{*}{ 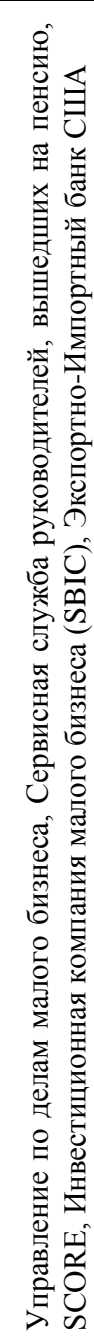 } & Поддержка инвесторов \\
\hline & & $\begin{array}{l}\text { Программа миграционной визы EB-5: возможность получения грин-карты } \\
\text { (постоянного проживания), включая супруга и не состоящих в браке детей, } \\
\text { при условии осуществления необходимых инвестиций в коммерческое пред- } \\
\text { приятие США и планировании создать/ сохранить } 10 \text { постоянных рабочих } \\
\text { мест с полной занятостью для квалифицированных работников из США. } \\
\text { Фонд кредитования малого бизнеса: предоставление капитала местным бан-- } \\
\text { кам и ссудным фондам развития собществ с целью их стимулирования рос- } \\
\text { та кредитования малого бизнеса. }\end{array}$ \\
\hline & & Поддержкка MCI (SCORE) \\
\hline & & $\begin{array}{l}\text { Инвестирование малого бизнеса с использованием государственных и част- } \\
\text { ных средств посредством: } \\
\text { кредитов (размер от } \$ 250 \text { тыс. до } \$ 10 \text { млн. с процентной ставкой от } 9 \text { до } \\
16 \% \text { ); } \\
\text { инвестиций (размер от } \$ 100 \text { тыс. до } \$ 5 \text { млн.) в обмен на долю собственности } \\
\text { компании; } \\
\text { комбинации кредитов и инвестиций. Процентная ставка по кредитам состав- } \\
\text { ляет от } 10 \text { до } 14 \% \text {. Объём инвестиций: от } \$ 250 \text { тыс. до } \$ 10 \text { млн. } \\
\text { Наиболее крупные программы: } 7 \text { (a) (кредитование программ развития мало-- } \\
\text { го бизнеса через предоставление гарантий: } 75 \% \text { для суммы не более } \$ 750 \\
\text { тыс.; } 80 \% \text { для суммы не более } \$ 100 \text { тыс.) и } \mathbf{5 0 4} \text { (кредитование с фиксирован- } \\
\text { ной ставкой для покупки недвижимого имущества, оборудования/технологий } \\
\text { на расширение и модернизацию предприятий) }\end{array}$ \\
\hline & & Поддержкка экспортёров \\
\hline & & $\begin{array}{l}\text { Экспортное финансирование в сочетании с торговыми консультациями и } \\
\text { обучением (SBA): } \\
\text { Гос. программа по расширению торговли (The State Trade Expansion Program) } \\
\text { на период с 2018-2021 гг.: предоставление грантов для малых предприятий } \\
\text { для участия в международных выставках и торговых миссиях в размере от } \\
\$ 1,750 \text { до } \$ 5,000 \text { в зависимости от вида деятельности; } \\
\text { Одобрение и страхование кредитов; } \\
\text { Кредитные средне- и долгосрочные гарантии с предоставлением } 85-\% \text { по- } \\
\text { крытия, } 15 \% \text { - первоначальный взнос покупателя при условии финансирова- } \\
\text { ния сроком до } 10 \text { лет (Экспортно-Импортный банк США). } \\
\text { Программа развития внешнего рынка / программа сотрудничества для фи- } \\
\text { нансирования производителей и переработчиков с/х продукции для продви- } \\
\text { жения товаров из США за границу. }\end{array}$ \\
\hline
\end{tabular}

Источник: составлено авторами

Одним из главных органов управления в сфере малого и среднего предпринимательства является Управление по делам малого бизнеса (Small Business Administration, $\mathrm{SBA}^{5}$ ) - единственное федеральное агентство, оказывающее всестороннюю помощь, предоставляя консультации (включая networking), финан-

\footnotetext{
${ }^{5}$ Small Business Administration. URL: https://www.sba.gov/ (дата обращения: 30.09.2020)
} 
совую поддержку, образование и экспертизу благодаря большому количеству служб и организаций в сотрудничестве с партнёрами для поддержки малого и среднего предпринимательства по различным направлениям [11, 12].

Во многом поддержка субъектов МСП и инвесторов (сотрудничающих с малым бизнесом) представлена в виде экономических методов, в частности, кредитования, страхование кредитов, инвестирования, государственное экономическое программирование, которые действуют исключительно на основании инструментов административно-правовых методов.

Данные методы нашли такое широкое распространение в силу того, что «капитал - это в первую очередь, топливо, которое стимулирует предпринимательство и экономический рост» ${ }^{6}$. Малому и среднему предпринимательству и стартапам необходим непрерывный приток капитала для осуществления запуска, конкуренции и дальнейшего роста компании.

Соответственно рост кредитования в стране, введение большого количества налоговых льгот, в частности благодаря «Закону о сокращении налогов и занятости» (от 2017 г.) обеспечивает многих предпринимателей самофинансированием в целях расширения бизнеса, реализации новых проектов, а также улучшений в области кадров (повышение сотрудников по карьерной лестнице или создание других преимуществ), что в конечном итоге способствует увеличению инвестиций и положительной экономической активности․

\section{Канада}

Территория Канады характеризуется особыми условия ведения бизнеса: далеко не во всех отраслях экономической деятельности малое и среднее предпринимательство является самодостаточным и нуждается в государственном капитале и нефинансовой поддержке (установление деловых отношений и сотрудничества, как внутри страны, так и за её пределами; консультации; образование; экспертиза; содействие в поиске данных о финансовом состоянии и деловой активности потенциальных иностранных партнёров и т.д.) в силу характерных суровых климатических условий и высоких транспортных издержек $[4,5]$.

Канада - это государство, для которого малое и среднее предпринимательство не менее значимо, чем для Соединённых Штатов Америки. Одним из подтверждений этому служит принятие первой из экономически развитых стран в 1988 г. программы «Национальная политика предпринимательской деятельности», закрепив тем самым постоянное совершенствование поддержки предпринимательства для его дальнейшего прогрессивного развития $[6,13,14]$.

Малые предприятия, с менее чем 100 сотрудниками составляют 97,9\% или в количественном выражении $=1152769$ предприятий (с менее чем 20 сотрудниками $=86,4 \%$ ) от общего числа всех предприятий малого бизнеса в стране ${ }^{8}$. Что также свидетельствует о высокой значимости и ответственности данных субъектов и в целом сектора малого бизнеса за обеспечение занятости значительной части населения рабочими местами.

Рассмотрим более подробно реализацию методов через инструменты государственного управления поддержки субъектов МСП на территории Канады (табл. 4).

Система поддержки МСП представляет собой «Канадскую Бизнес сеть» представляющую собой соглашение о сотрудничестве между федеральными министерст-

\footnotetext{
${ }^{6}$ Karen Kerrigan 2018 Policy Agenda for Entrepreneurs and Small Businesses - Issue Two: Access to Capital: SBE Council. URL: https://sbecouncil.org/2018/01/10/2018-policy-agenda-for-entrepreneurs-and-small-businesses-issue-two-access-to-capital/ (дата обращения 05.10.2020)

${ }^{7}$ The Small Business \& Entrepreneurship Council (SBE Council). URL: https://sbecouncil.org/ (дата обращения: 30.09.2020)

${ }^{8}$ Ключевая статистика малого бизнеса Канады - январь 2019. URL: https://www.ic.gc.ca/eic/site/061.nsf/eng/h_03090.html (дата обращения: 02.10 .2020 )
} 
вами и ведомствами, провинциальными и территориальными правительствами о содействии развитию и инновационной деятельности субъектам малого и среднего предпринимательства и характеризуется разнообразием программ, разрабатываемыми и реализуемыми Правительством и Банком развития бизнеса Канады [4].

Таблий 4

Методы, реализуемые государственными институтами и организациями в сфере МСП на территории Канады

\begin{tabular}{|c|c|c|}
\hline Методы & & Инструменты \\
\hline 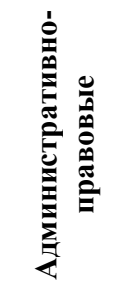 & \multicolumn{2}{|r|}{$\begin{array}{l}{ }^{1} \text { Закон об иммиграции и защите беженцев. Том } 151, \text { №33, } 2017 ;^{2} \text { Закон о департаменте } \\
\text { по делам индейцев и северному развитию (1985); Закон о финансовом управлении } \\
(1985 \text { с изменениями от } 11.04 .2020) \text {; Закон о фискальном управлении коренных наро- } \\
\text { дов (2005); Закон о департаменте по делам индейцев и северному развитию (1985); } \\
\text { ЗЗакон о финансировании малого бизнеса Канады (1998) с изменениями от 23.06.2015. }\end{array}$} \\
\hline \multirow{6}{*}{ 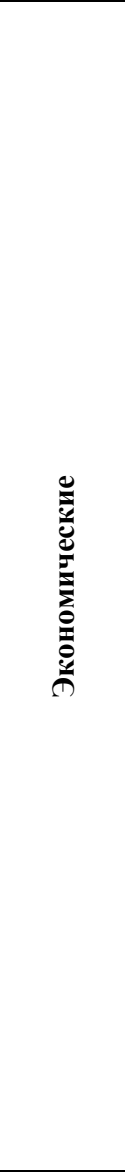 } & \multirow{6}{*}{ 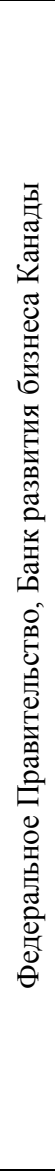 } & Поддержка инвесторов \\
\hline & & $\begin{array}{l}\text { Снижена ставка по налогу на инвестиции }=13,7 \% \text {; } \\
\text { Беспошлинная зона, позволяющая инвесторам импортировать передовые маши- } \\
\text { ны и оборудование от своих материнских компаний без импортных пошлин для } \\
\text { промышленных производителей сельского хозяйства. }\end{array}$ \\
\hline & & Поддержкка МСП \\
\hline & & $\begin{array}{l}\text { Кредит для малого бизнеса, размером до } \$ 100 \text { тыс. под } 4,55 \% \\
\text { Вместе с Futurpreneur Canada финансирование молодых предпринимателей в } \\
\text { возрасте от } 18 \text { до } 39 \text { лет на сумму до } \$ 60 \text { тыс. для открытия/развития бизнеса; } \\
\text { бизнес-кредит на покупку/обновление информационных и коммуникационных } \\
\text { технологий; } \\
\text { долгосрочное кредитование на отдельные цели до } 30 \text { лет на льготных условиях. } \\
\text { программа Start-up Visa }{ }^{1} \text { для приёма иностранных предпринимателей; } \\
\text { частные программы Start-up Visa для ускоренного получения вида на жительство } \\
\text { и увеличения числа резидентов; } \\
\text { налоговые льготы: по доходному налогу, инвестиционный налоговый кредит и } \\
\text { возврат средств. } \\
\text { программа финансирования малого бизнеса в Канаде: объём до } \$ 1 \text { млн. для каж- } \\
\text { дого заёмщика } \\
\text { кредиты для коренных народов для начала (до } \$ 150 \text { тыс.) и развития (до } \$ 250 \\
\text { тыс.) бизнеса: приобретение основных средств, для финансирования франшизы, } \\
\text { покрытие стартовых расходов, начало экспортирования и восполнение оборотно- } \\
\text { го капитала для поддержки роста компании }{ }^{2}\end{array}$ \\
\hline & & Поддержкка экспортёров \\
\hline & & $\begin{array}{l}\text { Страхование кредитов: } 90 \% \text { застрахованных убытков покрываются за счёт риска } \\
\text { неуплаты, вызванного различными событиями. } \\
\text { Программа инвестиций «Женщины в международной торговле»: предоставление } \\
\text { акционерного капитала через прямые инвестиции и инвестиции в канадские } \\
\text { фонды венчурного капитала; } \\
\text { Программа экспортных гарантий гарантирует до } 75 \% \text { внутренних активов, инди- } \\
\text { видуальные кредитные линии - до } 90 \% \text {, если гарантированная сумма меньше } \\
\$ 500 \text { тыс. }\end{array}$ \\
\hline
\end{tabular}

Источник: составлено авторами

Малое и среднее предпринимательство Канады представляет неоднородный и динамичный компонент экономики, который нуждается в разносторонней поддержке, как в целом, так и каждой составной категории: технологическое и научно-техническое, социальное, торговое, банковское, консультативное, женское предпринимательство, а также предпринимательство среди малочисленных народов и коренных наций. 
Среди представленной поддержки реализующихся методов государственного управления нашли распространение: государственное экономическое программирование, инвестирование, кредитование, страхование кредитов, льготное налогообложение и др., действующие в рамках принятых нормативно-правовых актов административно-правовых методов государственного управления.

В рамках деятельности Канадского Правительства существует значительное число программ экономического информирования и экономической поддержки. Можно отметить такие программы как: Community Futures Network of Canada (267 некоммерческих офисов по всей Канаде, каждый из которых предоставляет малому бизнесу ссуды, обучение и организацию мероприятий для начала и расширения бизнеса), Программа инвестиций «Женщины в международной торговле», Программа экспортных гарантий, Программа промышленного сотрудничества и другие [15].

В зависимости от провинций и территорий, поддержка через налогообложение и кредитование выражается таким образом: компании, имеющие объём продаж более $\$ 500$ тыс. в год, зарегистрированные более 2 лет, и имеющие в штате от 5 до 99 сотрудников, могут получить грант на покрытие 50\% расходов, которые связаны с выходом на внешний рынок (грант предоставляется в провинции Онтарио) [5].

Также предусмотрен грант на покрытие 50\% расходов, которые связаны с такими видами деятельности как: услуги по переводу документации, которая размещена на сайте компании, рассылка рекламных брошюр от компаний и т.д. (грант предоставляется в провинции Онтарио) [5].

Компании, которые прошли отбор, могут получить безвозмездную финансовую помощь в виде грантов или премий, гарантии под кредиты других финансовых институтов (например, частных фондов), долгосрочные беспроцентные или льготные займы, и прочую финансовую поддержку [5].

\section{Заключение}

Проведённое исследование было посвящено систематизации зарубежного опыта в направлении использования методов и инструментов государственного управления функционированием малого и среднего предпринимательства, в ходе которого получены соответствующие цели результаты:

1) рассмотрены трактовки «методов государственного управления», на основании анализа которых были выделены схожие черты и дано обобщающее авторское определение метода государственного управления;

2) выделены подходы: классический и аспектный к классификации методов государственного управления, в основе которых критерии воздействия и происхождения;

3) представлена в дополнение подробная классификация, объединяющая в себе расширенный набор критериев для выделения и включения методов, отличных от методов классического и аспектного подходов;

4) раскрыто содержание базовых методов государственного управления: административно-правовых и экономических через определение и обоснование их выбора;

5) представлена реализация выбранных методов через инструменты зарубежных федеральных органов исполнительной власти таких как Правительство, федеральное Министерство, правительственные организации и государственный гарантийный фонд, а также Правительственных банков в таких странах как США и Канада. 
Таким образом, решённые задачи, необходимые для достижения цели, сделали возможной систематизацию зарубежного опыта методов и инструментов государственного управления предпринимательством (табл. 5).

Таблица 5

Реализация административно-правовых и экономических методов в США и Канаде

\begin{tabular}{|c|c|}
\hline $\begin{array}{c}\text { Административно- } \\
\text { правовые методы }\end{array}$ & Инструменты \\
\hline $\begin{array}{c}\text { Закон о предприни- } \\
\text { мательстве }\end{array}$ & $\begin{array}{l}\text { США: Закон о малом бизнесе; Закон об инвестициях в малый бизнес. } \\
\text { Канада: Закон о финансировании малого бизнеса Канады; Закон об имми- } \\
\text { грации и защите беженцев. }\end{array}$ \\
\hline $\begin{array}{c}\text { Экономические } \\
\text { методы }\end{array}$ & Инструменты \\
\hline Кредитование & $\begin{array}{l}\text { США: Фонд кредитования малого бизнеса предоставляет капитал местным } \\
\text { банкам и ссудным фондам; программы: } 7(\text { a) и } 504 ; \text { кредиты размером от } \\
\$ 250 \text { тыс. до } \$ 10 \text { млн. с процентной ставкой от } 9 \text { до } 16 \% \text {. } \\
\text { Канада: кредит размером до } \$ 100 \text { тыс. под } 4,55 \% \text {; бизнес-кредит на покуп- } \\
\text { ку/обновление информационных и коммуникационных технологий; долг-- } \\
\text { срочное кредитование на отдельные цели до } 30 \text { лет на льготных условиях; } \\
\text { кредиты для коренных народов. }\end{array}$ \\
\hline $\begin{array}{c}\text { Страхование креди- } \\
\text { тов }\end{array}$ & $\begin{array}{l}\text { США: Экспортно-Импортный банк США предоставляет кредитные средне- } \\
\text { и долгосрочные гарантии с предоставлением 85-\% покрытия. } \\
\text { Канада: страхование кредитов в размере } 90 \% \text { застрахованных убытков. }\end{array}$ \\
\hline Инвестирование & $\begin{array}{l}\text { США: инвестиции размером от } \$ 100 \text { тыс. до } \$ 5 \text { млн } \\
\text { Канада: инвестиции в молодых предпринимателей размером до } \$ 60 \text { тыс. } \\
\text { для открытия/развития бизнеса. }\end{array}$ \\
\hline $\begin{array}{l}\text { Государственное } \\
\text { экономическое про- } \\
\text { граммирование }\end{array}$ & $\begin{array}{l}\text { США: Государственная программа по расширению торговли; Государствен- } \\
\text { ная программа сотрудничества для финансирования производителей и пере- } \\
\text { работчиков с/х продукции для продвижения товаров из США за границу. } \\
\text { Канада: программа Start-up Visa для приёма иностранных предпринимате-- } \\
\text { лей и её частные программы для ускоренного получения вида на жительст- } \\
\text { во; Программа инвестиций «Женщины в международной торговле»; Про- } \\
\text { грамма экспортных гарантий. }\end{array}$ \\
\hline
\end{tabular}

Источник: составлено авторами

Приведённые конкретные меры и инструменты, выражающие исполнение методов государственного управления, позволили выделить схожие черты в системе поддержки предпринимательства:

-реализация группы экономических методов государственного управления представлена через такие частные методы как: государственное экономическое программирование, инвестирование, инвестиционное страхование, кредитование, страхование кредитов, льготное и дифференцированное налогообложение, выработка и реализация системы приоритетов, государственные гарантии и др., действующие в рамках принятых нормативно-правовых актов административно-правовых методов государственного управления;

-анализируя инструменты реализации обозначенных методов следует отметить наличие, в частности высокие гарантии по банковским кредитам в размере от 75 до $85 \%$ и низкие процентные ставки по кредитам в размере от 3 до 5\%.

Выделенные инструменты в системе поддержки предпринимательства, в частности высокие гарантии по банковским кредитам в размере от 75 до $85 \%$ и низкие процентные ставки по кредитам в размере от 3 до 5\%, позволяют их считать возможными и достойными инструментами для внедрения в практику на территории Российской Федерации в систему государственного регулирования малого и среднего предпринимательства в качестве полезного опыта.

Изученный зарубежный опыт государственного управления функционированием предпринимательства свидетельствует о разносторонней поддержке 
его развития. В связи с чем возникает необходимость в выстраивании грамотной системы управления бизнесом, исследуя и перенимая для этого имеющийся опыт, чтобы создать всё необходимое, что требуется в настоящее время малому и среднему предпринимательству.

Впоследствии созданные условия, позволяющие предпринимательству, особенно малому и среднему, развиваться, будут способствовать динамичному и прогрессивному развитию территории и повышению благосостояния населения.

\section{Список источников / References}

1. Кулаков В.Н. Малое и среднее предпринимательство в республике Беларусь. Проблемы экономики, 2019, №2, сc. 123-321. [Kulakov V.N. Maloe i srednee predprinimatel'stvo $\mathrm{v}$ respublike Belarus' [Small and medium business in the Republic of Belarus]. Problemy ekonomiki = Economic problems, 2019, no. 2, pp. 123-321.]

2. Теребова С.В. и др. Предпринимательство в регионе: состояние, перспективы: монография. Вологда: ИСЭРТ РАН, 2011. 160 с. [Terebova S.V. Predprinimatel'stvo v regione: sostoyaniye, perspektivy: [Entrepreneurship in the region: state, prospects]. Vologda: ISERT RAN, 2011, 160 p.]

1. Lisowska R. The Potential of Business Environment Institutions and the Support for the Development of Small and Medium-sized Enterprises. Entrepreneurial Business and Economics Review, 2016, no. 4 (3), pp. 85-101.

2. Бородкина В.В., Москвина А.В., Рыжкова О.В., Улас Ю.В. Государственная поддержка субъектов малого и среднего бизнеса северных стран: Канада, США, Финляндия, Швеция. Российское предпринимательство, 2015, №16 (21), сс. 3743-3764. [Borodkina V.V., Moskvina A.V., Ryzhkova O.V., Ulas Yu.V. Gosudarstvennaya podderzhka sub"yektov malogo i srednego biznesa severnykh stran: Kanada, SSHA, Finlyandiya, Shvetsiya [State support of small and medium-sized businesses in the northern countries: Canada, USA, Finland, Sweden]. Rossiyskoye predprinimatel'stvo $=$ Russian Journal of Entrepreneurship, 2015, no. 16 (21), pp. 3743-3764.]

3. Кудряшов В.С. Стимулирование и поддержка экспорта предприятий малого и среднего бизнеса в Российской Федерации и за рубежом. Juvenis scientia, 2018, №9, cc. 25-29. [Kudryashov V.S. Stimulirovaniye i podderzhka eksporta predpriyatiy malogo i srednego biznesa $v$ Rossiyskoy Federatsii i za rubezhom [Stimulating and supporting the export of small and medium-sized businesses in the Russian Federation and abroad]. Juvenis Scientia, 2018, no. 9, pp. 25-29.]

3. Условия и перспективы развития среднего и малого бизнеса в Канаде, 2011. Available at: https://ru.exrus.eu/Usloviya-i-perspektivy-razvitiya-srednego-i-malogo-biznesa-vKanade-id4e6e13896ccc19493c0030c3/Artikel1 (accessed: 12.10.2020 г.)

4. Kovtunenko Yu.V., Valyanskaya A.A., Miroshnykova K.A. Economic analysis and its importance in the management of enterprise. Economics: time realities, 2017, no. 1 (29), cc. $80-85$.

5. Bamberger M., Rugh J., Mabry L. RealWorld Evaluation: Working under Budget, Time, Data and Political Constraints. Thousand Oaks, CA, 2007. 75 p.

4. Мысаченко В.И. Методы и инструменты государственного регулирования структурных преобразований промышленности. Вестник Томского государственного универcumema, 2009, №323, cc. 268-272. [Mysachenko V.I. Metody i instrumenty gosudarstvennogo regulirovaniya strukturnykh preobrazovaniy promyshlennosti [Methods and tools for state regulation of structural changes in industry]. Vestnik Tomskogo gosudarstvennogo universiteta $=$ Tomsk State University Bulletin, 2009, no. 323, pp. 268-272.]

6. Wilson J. Essentifls of business research: A guide to doing your research project. Sage, 20, 2014. $376 \mathrm{p}$.

7. Dilger R.J., Gonzales O.R. SBA Small Business Investment Company Program. Journal of Current Issues in Finance, Business and Economics, 2012, vol. 5, no. 4, pp. 407-417. 
8. George Solomon, Mark Carney United States Small Business Administration's Role in Small Business Training. International Small Business Journal: Researching Entrepreneurship, 2016, vol. 4, no. 1, pp. 25-33.

9. Jill Grant, Planning the Good Community: New Urbanism in Theory and Practice. Taylor \& Francis, 2006. 269 p.

10. Brendan Roziere, Kevin Walby The duty to assist in Canadian Freedom of Information law. Canadian Public Administration, 2020. Doi:10.1111/capa.12392.

11. Logan M. Lawrence, Katherine Fierlbeck, Patrick J. McGrath, Janet A. Curran. An expert-generated tool for assessing policy capacity. Canadian Public Administration, 2020. Doi.org/10.1111/capa.12364.

\section{Сведения об авторах / About authors}

Калинина София Леонидовна, инженер-исследователь, Вологодский научный центр Российской академии наук. 160014 Россия, Вологда, ул. Горького, 56А. E-mail: sonechka-kalinina1997@ mail.ru Sofia L. Kalinina, Research Engineer, Vologda Research Center, RAS. 56A Gorkogo str., Vologda, Russia 160014. E-mail: sonechka-kalinina1997@mail.ru

Кузнецова Екатерина Петровна, младший научный сотрудник, Вологодский научный центр Российской академии наук. 160014 Россия, Вологда, ул. Горького, 56А.

E-mail:333.maarel.333@mail.ru

Ekaterina P. Kuznetsova, Junior Researcher, Vologda Research Center, RAS. 56A Gorkogo str., Vologda, Russia 160014.E-mail: 333.maarel.333@mail.ru 